https://www.amerabra.org; https://fspu.uitm.edu.my/cebs; https://www.emasemasresources.com/

$5^{\text {th }}$ ABRA International Conference on Quality of Life

Holiday Villa Langkawi, Langkawi Island, Malaysia, 15-16 Dec 2021

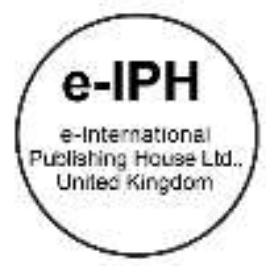

\title{
Socio-demographic Factors and Eating Behaviours among Nurses in a Teaching Hospital
}

\author{
Norfidah Mohamad, Zamzaliza Abdul Mulud, Ira Nadhira Ruzli, Nur Ain Farhah Mohd Zainun Zaman \\ Centre for Nursing Studies, Faculty of Health Sciences \\ Universiti Teknologi MARA Selangor, Puncak Alam Campus, Malaysia
}

norfidah@uitm.edu.my, zamzaliza@uitm.edu.my, diraruzli@gmail.com, ainmzz98@gmail.com

Tel: +60332584356

\begin{abstract}
Nurses are known as shift workers. Shift work can disrupt regular meal habits resulting in abnormal eating behaviour. Hence, this study aims to determine the relationship between socio-demographic factors and eating behaviour. A cross-sectional study was conducted among 135 nurses using a selfadministered questionnaire. This study found that the shift duties factor was significantly associated with emotional and external eating behaviour. This might be caused by how nurses cope with the burden of shift works. Health promotion strategies from both individuals and organisations should be intensified for these nurses to enhance healthy eating habits and promote healthy lifestyles.
\end{abstract}

Keywords: eating behaviour; shift duty; nurses

eISSN: 2398-4287@ 2021. The Authors. Published for AMER ABRA cE-Bs by e-International Publishing House, Ltd., UK. This is an open access article under the CC BYNCND license (http://creativecommons.org/licenses/by-nc-nd/4.0/). Peer-review under responsibility of AMER (Association of Malaysian Environment-Behaviour Researchers), ABRA (Association of Behavioural Researchers on Asians/Africans/Arabians) and cE-Bs (Centre for Environment-Behaviour Studies), Faculty of Architecture, Planning \& Surveying, Universiti Teknologi MARA, Malaysia. DOI: https://doi.org/10.21834/ebpj.v6i18.3071

\subsection{Introduction}

Eating behaviour refers to a complex interaction between physiological, psychological, and social factors that affect meal timing, food intake quality, and food preference Almajwal (, 2016). Shift work duties might influence abnormal eating behaviours among nurses. It was proven by the statements obtained in several research studies globally. According to Almajwal (2016), a study conducted among women nurses in Saudi hospitals found that rotating shift duty nurses are more likely to have abnormal restrained eating habits and less likely to have abnormal external eating behaviour. In addition, a study conducted at South Carolin stated that the dietary habits of nurses during work differ from home due to work shifts and nurses tend to eat a little or late at night due to their shift work (Horton Dias \& Dawson, 2020). These practices will eventually affect their overall health status, which is considered flawed as working as front-liners requires a good and healthy body.

Shift work was characterised as work outside daytime hours, including rotating or erratic schedules and work at night and evening (Min Ju et al., 2013). For nurses, shift work is an essential part of their working career. That is why abolishing these work practices for hospital-based nurses is neither reasonable nor feasible. The reason is that 24-hours scheduling is necessary to provide undisturbed patient care (Matheson et al., 2014 as cited in Gifkins et al., 2018) to ensure that all the care and treatments are provided for the patients.

However, maintaining a good health status even while working is a must engraved statement in all workers' minds because shift works' health implications have been extensively studied (Gupta et al., 2019). The work of nurses is frequently unpredictable and extremely time-sensitive, forcing them to change their eating habits to fulfil their job requirements, resulting in abnormal eating behaviour. The

eISSN: 2398-4287@ 2021. The Authors. Published for AMER ABRA cE-Bs by e-International Publishing House, Ltd., UK. This is an open access article under the CC BYNCND license (http://creativecommons.org/licenses/by-nc-nd/4.0/). Peer-review under responsibility of AMER (Association of Malaysian Environment-Behaviour Researchers), ABRA (Association of Behavioural Researchers on Asians/Africans/Arabians) and cE-Bs (Centre for Environment-Behaviour Studies), Faculty of Architecture, Planning \& Surveying, Universiti Teknologi MARA, Malaysia.

DOI: https://doi.org/10.21834/ebpj.v6i18.3056 
previous study by Shafi et al. (2020) found that shift employees have more negative eating patterns than day workers. Therefore, even though it is bad for their well-being, many nurses appear to have abnormal eating behaviour. This study aims to determine the relationship between socio-demographic factors and eating behaviour.

\subsection{Literature Review}

Eating behaviour is complex and results from such factors as dietary habits and preferences, response to hunger, individuals' and societal norms, the food environment, and the time available to eat (Buss, 2012). Based on the article reviewed, only $57 \%$ reported eating breakfast daily, which showed that healthy eating behaviour might not be a predominant pattern presented in the nursing profession. Besides that, it found that shift workers' total energy intake was less than day workers. The difference could probably be attributed to lower meal frequency and poorer quality of meals during night shifts (Wong et al., 2010). Many factors may contribute to the alteration of eating habits among nurses. For example, these peculiar eating habits could influence time limits, food availability, weariness, stress, and changing social patterns. Hence, proving shift employment messes with people's social lives and dietary habits (Akmaliyah, 2013). The same statement was written by Shafi et al. (2020), who stated that long working hours, shift work, the availability of fast food, eating as a maladaptive coping convenience in response to stress, environmental factors, and the nature of food outside of working hours may lead to poor dietary habits, negatively affecting their productivity.

Most nurses who work shift duty eat more fast food and snacks and fewer vegetables. They are reported by the study of Wong et al. (2010), which showed that nurses working night shifts preferred fast food and more snacks to keep them awake and maintain energy due to their heavy workload. Night shift nurses are more likely to forget breakfast. They prefer choosing to sleep rather than eat when they arrive home (Gupta et al., 2019).

Another study by Almajwal (2016) in Saudi Arabia stated that those with diplomas were more likely to engage in restrained eating, emotional eating, and external eating than those with a higher educational level. The article shows that the level of education may also impact eating behaviour. Other than that, this statement from the author showed that individuals with higher education had better control of eating behaviour than undergraduates. A study from Ain Sham University Hospital discovered that the percentage of nurses who worked more than ten years and ate an unhealthy diet was significantly higher than the percentage of nurses who worked less than five years and ate an unhealthy diet (Hakim et al., 2016). This may happen due to workload increases.

Aside from all the negative health implications mentioned above, several studies have found that shift employment can disrupt family relationships (Tai et al., 2014). In Iran, a study conducted by Akbarzadeh et al. (2017) stated that eating behaviour positively correlated with weight, BMI, and waist circumference. The same study conducted in Iran also noted that restrained eating was significantly higher in overweight and obese participants than normal weight (Akbarzadeh et al., 2017). Study outcomes revealed that night shift employment impacted eating habits and food choices, leading to unhealthy eating patterns among Lebanese nurses. The data showed that night shift work causes an imbalanced diet and decreased physical activity in night shift nurses (Samhat et al., 2020). Findings from this study may identify factors associated with disordered eating behaviours in this population.

\subsection{Methodology}

\subsection{Sample}

A cross-sectional study was applied in this research. This study population involved all nurses working at the UiTM Medical Specialist Centre, Sungai Buloh. A purposive sampling method was chosen for this research with a sample size of 135 . The inclusion criteria were male and female nurses who worked shift duty and office hours. The exclusion criteria were nurses who were on maternity leave and sick leave.

\subsection{Instruments}

The Dutch Eating Behaviour Questionnaire (DEBQ) Malay version was adopted from previous research for this study. The questionnaire is divided into two sections. In section $A$, the questions are on the socio-demographic factors of the respondents. While in section $B$ comprises of DEBQ questionnaire of 33 items to measure emotional, external, and restrained eating behaviour. Provided that, the emotional eating behaviour was assessed by 13 items, whereas the external and restrained eating behaviours were assessed by ten items each using the 5-point Likert scale ranging from 1 (seldom) to 5 (very often), with the exception being item 21, which required reverse scoring. The cutoff means Likert scale score was 1.33, which was calculated by subtracting the highest possible score (5) from the lowest possible score (1) and multiplying by the number of categories (3). Each subscale's total score was computed by summing all of the items in each domain, and then the mean of the total score was separated into three categories of low, moderate, and high (Siew Hong, 2019).

\subsection{Data collection methods}

Ethical approval and permission to conduct this study were granted from the Research Ethics Committee, UiTM Shah Alam, and UiTM Medical Specialist Centre, Sungai Buloh. The data was collected after screening for the eligibility of the respondents according to inclusion and exclusion criteria. The participants have then explained the objectives of this study. The ones who agreed with the terms of participating in the study were asked to sign their consent before answering the questionnaire to ensure the confidentiality of all the information gathered. To not disturb the nurses' jobs, the self-administered questionnaire was distributed and given to the respondents after shift hours or when they were not busy and collected at that time. It required five to ten minutes to complete the questionnaire. Despite that, the questionnaires 
were also checked thoroughly to ensure they were responded to and fulfilled without being missed. All the data obtained were recorded carefully.

\subsection{Statistical analysis}

Complete questionnaires were analysed using IBM Statistical Package for the Social Sciences (SPSS) for windows version 25.0. The descriptive analysis method is used to test and analyse the level of abnormal eating behaviour among nurses. Chi-Square test and Fisher's Exact Test were used to determine the relationship between socio-demographic data and abnormal eating behaviour among nurses.

\subsection{Findings}

\subsection{Demographic data}

The demographic data for this study is shown in Table 1. According to the results, the mean age of all participants was 29 years old, with a value of $28.64 \pm 4.231$. The majority of the nurses working in this hospital are below 30 years $(n=96 ; 71.1 \%)$, with female nurses having the highest percentage of participation with $90.4 \%(n=122)$. The highest percentage of nurses, with $29.6 \%(n=40)$ working in the ward. From the table, half of the nurses were single compared to another marital status, as evidenced by a proportion of $49.6 \%(n=67)$. The mean years of working experience were six years, with the value of $5.61 \pm 3.81$ and $71(52.6 \%)$ participants worked in the hospital for 1 to 5 years. Besides, more than half of the participants were graduated as diploma students $(n=98 ; 72.6 \%)$. Most of the participants in this study had normal BMI $(n=54 ; 40 \%)$. The researchers derived that more than half of the nurses worked with shift duty, $83.0 \%(n=112)$. Lastly, half of the nurses had 1 to 3 times night shifts per month ( $n=68 ; 50.4 \%)$.

Table 1: Frequency and percentage of socio-demographic factors $(n=135)$

\begin{tabular}{|c|c|c|}
\hline Variables & Mean $\pm S D /(n)$ & Percentage $(\%)$ \\
\hline Age & $28.64 \pm 4.231$ & \\
\hline$\leq 30$ years old & 96 & 71.1 \\
\hline $31-38$ years old & 36 & 26.7 \\
\hline$\geq 38$ years old & 3 & 2.2 \\
\hline \multicolumn{3}{|l|}{ Gender } \\
\hline Male & 13 & 9.6 \\
\hline Female & 122 & 90.4 \\
\hline \multicolumn{3}{|l|}{ Department } \\
\hline Ward & 40 & 29.6 \\
\hline Clinic & 23 & 17.0 \\
\hline Intensive Care Unit (ICU) & 13 & 9.6 \\
\hline Cardiac Care Unit (CCU) & 18 & 13.3 \\
\hline Operation Theatre (OT) & 34 & 25.2 \\
\hline Emergency Department (ED) & 7 & 5.2 \\
\hline \multicolumn{3}{|l|}{ Marital Status } \\
\hline Single & 67 & 49.6 \\
\hline Married & 65 & 48.1 \\
\hline Divorced & 3 & 2.2 \\
\hline Years of Working Experience & $5.61 \pm 3.81$ & \\
\hline $1-5$ years & 71 & 52.6 \\
\hline $6-10$ years & 48 & 35.6 \\
\hline$>11$ years & 16 & 11.9 \\
\hline \multicolumn{3}{|l|}{ Highest Level of Education } \\
\hline Diploma & 98 & 72.6 \\
\hline Degree & 37 & 27.4 \\
\hline Body Mass Index (BMI) & $24.37 \pm 5.13$ & \\
\hline Underweight & 13 & 9.6 \\
\hline Normal Weight & 54 & 40 \\
\hline Pre-Obese & 32 & 23.7 \\
\hline Obese I & 30 & 22.2 \\
\hline Obese II & 4 & 3.0 \\
\hline Obese III & 2 & 1.5 \\
\hline \multicolumn{3}{|l|}{ Working Hour } \\
\hline Office Hour & 23 & 17.0 \\
\hline Shift Duty & 112 & 83.0 \\
\hline \multicolumn{3}{|l|}{ Frequency Of Night Shift Per Month } \\
\hline Nil & 23 & 17.0 \\
\hline 1-3 Times Per Month & 68 & 50.4 \\
\hline$>4$ Times Per Month & 44 & 32.6 \\
\hline
\end{tabular}

\subsection{Level of eating behaviour}

These research findings show that the nurses experienced emotional eating behaviour. To be specific, most of the nurses in this study had a moderate level of emotional eating behaviour $(n=73 ; 54.1 \%)$. At the same time, the rest of the nurses had low $(n=39 ; 28.9 \%)$ and high levels of emotional eating behaviour $(n=23 ; 17.0 \%)$. Furthermore, it also showed that the nurses also had an external type of eating 
behaviour. Most of the nurses experienced high external eating behaviour ( $n=65 ; 48.1 \%)$, while a total number of $64(47.4 \%)$ nurses had moderate external eating behaviour. Only six nurses (4.4\%) had low external eating behaviour in this study. Half of the respondents $(n=68 ; 50.4 \%)$ had a moderate level of restrained eating, followed by $29.6 \%(n=40)$, who experienced a low level of restrained eating. Meanwhile, only $20.0 \%(n=27)$ had high restrained eating.

\subsection{Relationship between Socio-demographic factors and eating behaviour}

Table 2 shows that emotional eating behaviour was significantly differences with the department $(x 2: 20.21 ; p=0.03)$, marital status $(x 2$ : $13.94 ; p<0.01)$, working hours $(x 2: 8.18 ; p=0.02)$ and frequency of night shift per month $(x 2: 17.15 ; p<0.01)$. Besides that, there was also a statistically significant between external eating behaviour with department $(x 2: 17.78 ; p=0.03)$, marital status $(x 2: 9.89 ; p=0.03)$, years of working experience $(x 2: 10.04 ; p=0.03)$, highest level of education $(x 2: 13.38 ; p<0.01)$, working hours $(x 2: 10.22 ; p<0.01)$ and frequency of night shift per month $(x 2: 14.85 ; p<0.01)$. However, for restrained eating behaviour it shows that only marital status $(x 2: 9.01 ; p=0.04)$ was significantly difference.

Table 2: Relationship between socio-demographic factors and eating behaviour

\begin{tabular}{|c|c|c|c|c|c|c|}
\hline \multirow[t]{3}{*}{ Socio-demographic data } & \multicolumn{6}{|c|}{ Eating behaviour } \\
\hline & \multicolumn{2}{|c|}{ Emotional } & \multicolumn{2}{|c|}{ External } & \multicolumn{2}{|c|}{ Restrained } \\
\hline & stat(df) & $P$-value & stat(df) & $P$-value & $\operatorname{stat}(d f)$ & $P$-value \\
\hline Age & $6.03(4)$ & $0.15^{\mathrm{a}}$ & $6.25(4)$ & $0.15^{\mathrm{a}}$ & $1.95(4)$ & $0.80 \mathrm{a}$ \\
\hline Gender & $0.76(2)$ & $0.73^{a}$ & $0.68(2)$ & $0.71^{\mathrm{b}}$ & $1.18(2)$ & $0.64^{a}$ \\
\hline Department & $20.21(10)$ & $0.03^{b}$ & $17.78(10)$ & $0.03 \mathrm{a}$ & $12.79(10)$ & $0.21 \mathrm{a}$ \\
\hline Marital Status & $13.94(4)$ & $0.00 \mathrm{a}$ & $9.89(4)$ & $0.03^{\mathrm{a}}$ & $9.01(4)$ & $0.04^{a}$ \\
\hline Years Of Working Experience & $6.36(4)$ & $0.17^{a}$ & $10.04(4)$ & $0.03^{a}$ & $6.70(4)$ & $0.15^{\mathrm{a}}$ \\
\hline Highest Level Of Education & $5.53(2)$ & $0.06^{b}$ & $13.38(2)$ & $0.00^{\mathrm{a}}$ & $2.70(2)$ & $0.26^{b}$ \\
\hline Body Mass Index (BMI) & $7.35(10)$ & $0.68^{a}$ & $13.09(10)$ & $0.17 \mathrm{a}$ & $9.49(10)$ & $0.44^{a}$ \\
\hline Working Hour & $8.18(2)$ & $0.02^{\mathrm{b}}$ & 10.22(2) & $0.00 \mathrm{a}$ & $0.94(2)$ & $0.63^{b}$ \\
\hline Frequency Of Night Shift Per Month & $17.15(4)$ & $0.00^{\mathrm{b}}$ & $14.85(4)$ & $0.00^{\mathrm{a}}$ & $1.71(4)$ & $0.79 \mathrm{~b}$ \\
\hline
\end{tabular}

\subsection{Discussion}

\subsection{Level of eating behaviour}

This study revealed that most of the nurses working shift duty were most likely experienced moderate emotional eating behaviour and moderate, restrained eating behaviour. However, they were less likely to experience a high level of external eating behaviour. It was in line with the study performed by Wong et al. (2010). The results were that the number of participants having emotional and restrained eating behaviour was higher than external eating behaviour. However, these findings contradicted the study written by Siew Hong (2019). It reported the nurses were more prone to experience moderate external eating and moderate restraint eating behaviour while less likely to experience emotional eating behaviour.

\subsection{Relationship between socio-demographic factors and eating behaviour}

This study showed no significant relationship between respondents' age with eating behaviour. A similar study conducted by Wong et al. (2010) found no significant difference between age and eating behaviour. However, a study by Ferreira-Pêgo et al. (2020) stated that age was statistically significant with restrained eating behaviour. It shows that eating behaviour does not influence age. The result in gender and eating behaviour was found not significant. A previous article mentioned gender variations in subject reports of meal choices when exposed to external stress eating. In their study, Wong et al. (2010) also mentioned that most nurses were female. In this study, the small number of male nurses may cause insignificant differences between gender and eating behaviour.

It showed a significant difference between departments with emotional and external eating behaviour. In a nutshell, lousy eating behaviour may result from overworked in their respective fields. It was clarified by Horton Dias \& Dawson (2020) where nurses cannot leave their position or patients. That was why nurses often skipped breaks. Other than that, there was a statistically significant between marital status with all eating behaviour.

In contrast, a study by Wong et al. (2010) showed no significant difference between marital status with all eating behaviour; meanwhile, a study conducted by Almajwal (2016) stated a significant relationship between marital status with restrained and external eating behaviour. Married nurses working rotation shifts had higher work-family conflict than married nurses working day shifts (Tai et al., 2014). Thus, different marital statuses brought varied challenges and duties to each person, affecting their eating pattern.

Years of working experience have a significant relationship with external eating behaviour. According to a study conducted by Wong et al. (2010), there was a favourable connection between long-term nurses and external eating habits. The same study found that nurses with more than ten years of experience were more prone to have emotional eating behaviour. Nursing professionals with over ten years of experience are likely to be stressed and influence their eating behaviour. The highest level of education also had a significant relationship with external eating behaviour. However, a previous study by Almajwal (2016) mentioned that the education level was significantly 
associated with all eating behaviour styles. People with lower education eat more unhealthy foods. A German study indicated that those with lower education eat more sugar and fat-rich diets while a high level of education drinks less alcohol (Finger et al., 2013). In conclusion, persons with greater education were more mindful of their eating habits than others.

Also, this study showed that there was no significant relationship reported between BMI with all types of eating behaviour. Research conducted by (Akbarzadeh et al., 2017; Siew Hong, 2019 and Almajwal, 2016) said a significant relationship between restrained eating behaviour and BMI. It shows the insignificant between both variables in this study may be due to the nurses' inaccurate body mass and height. Another socio-demographic factor, frequency of night shift per month, revealed significant differences with emotional and external eating behaviour. A study conducted by Wong et al. (2010) stated that nurses who worked once to thrice night shifts per month were more likely to experience restrained eating behaviour. However, in their study, Akbarzadeh et al. (2017) found no significant differences between the number of night shifts with abnormal eating behaviour. Nurses were required to stay awake all night to do their tasks, which was bound to be stressful and exhausting. As a result, they will crave sweets and seek snacks all night because it is an effective stress reliever for night shift workers.

The result also showed a significant difference between shift duty with emotional and external eating behaviour. In contrast, a previous study by Almajwal (2016) demonstrated that the shift duty was significant with restrained and external eating behaviour. In addition, this result was different from a study by Wong et al. (2010), which reported a significant association between shift duty with emotional and restrained eating behaviour. The results suggest that these nurses' emotional and external eating behaviours may be due to some factors. A study conducted by Monaghan et al. (2018) stated that nurses were hesitant to take breaks and frequently failed to take all their scheduled breaks. Consumption of high-sugar foods to relieve cravings and exhaustion during shift work is one example (Wong et al., 2010). The feelings of tiredness and craving showed the emotional causes of this unhealthy behaviour. Nurses tend to have hardships, and maybe the reason for external eating behaviour occurred among nurses.

\subsection{Conclusion \& Recommendations}

The results show that only emotional and external eating behaviour had a significant relationship with shift duty factors among nurses. It can be concluded that these two eating behaviours might be caused by how the nurses came to cope with the burden of shift works or their environment and surroundings. Other than that, the working hours of nurses are also one of the factors that lead to abnormal eating behaviour, as most of the participants worked shift duty.

There were a few limitations in this study. However, due to the current world problem, which is Covid-19, data collection became restricted. It was why the total number of respondents was only 135 nurses. Apart from that, the majority of our respondents were female, with only a handful of male nurses. This poor representativeness of the population may affect our result. Moreover, the study setting was also limited to one teaching hospital. Hence, health promotion strategies from both individuals and organisations should be intensified for these nurses to enhance healthy eating habits and promote healthy lifestyles. The scope of future studies should be broadened to include a larger sample size from different hospitals. It could explore qualitative research by interviewing nurses throughout their shifts to learn more about their eating habits.

\section{Acknowledgement}

The author gratefully acknowledges the support of Universiti Teknologi MARA (UiTM), the Centre for Nursing Studies, Faculty of Health Sciences, UiTM, and the UiTM Medical Specialist Centre Sungai Buloh. In addition, the authors also would like to express their greatest gratitude to everyone for their important contribution to this research, whether directly or indirectly.

\section{Paper Contribution to Related Field of Study}

This study's findings will help the organisation plan strategies that should be intensified to increase the awareness and the importance of healthy eating habits during the shift.

\section{References}

Akbarzadeh, M., Mohabati, S., Sohrabi, Z., \& Eftekhari, M. H. (2017). Eating Behaviour and its Association with Night Work and BMI among Female Nurses in Shiraz Hospitals, Iran. International Journal of Nutrition Sciences, 2(3), 146-151. http://ijns.sums.ac.ir/index.php/lJNS/article/view/57

Akmaliyah, M. (2013). 済無No Title No Title. Journal of Chemical Information and Modeling, 53(9), 1689-1699

Almajwal, A. M. (2016). Stress, shift duty, and eating behaviour among nurses in Central Saudi Arabia. Saudi Medical Journal, 37(2), 191-198. https://doi.org/10.15537/smj.2016.2.13060

Buss, J. (2012). Associations between Obesity and Stress and Shift Work among Nurses. Workplace Health \& Safety, 60(10), 453-458. https://doi.org/10.1177/216507991206001007

Ferreira-Pêgo, C., Rodrigues, J., Costa, A., \& Sousa, B. (2020). Eating behaviour: The influence of age, nutrition knowledge, and Mediterranean diet. Nutrition and Health, 26(4), 303-309. https://doi.org/10.1177/0260106020945076 
Finger, J. D., Tylleskär, T., Lampert, T., \& Mensink, G. B. M. (2013). Dietary behaviour and socioeconomic position: The role of physical activity patterns. PLoS ONE, 8(11). https://doi.org/10.1371/journal.pone.007839

Gifkins, J., Johnston, A., \& Loudoun, R. (2018). The impact of shift work on eating patterns and self-care strategies utilised by experienced and inexperienced nurses. Chronobiology International, 35(6), 811-820. https://doi.org/10.1080/07420528.2018.1466790

Gupta, C. C., Coates, A. M., Dorrian, J., \& Banks, S. (2019). The factors influencing the eating behaviour of shiftworkers: What, when, where and why. Industrial Health, 57(4), 419-453. https://doi.org/10.2486/indhealth.2018-0147

Hakim, S. A., Eldin, W. S., \& Mohsen, A. (2016). Dietary behaviour and its relation with lifestyle, rotating work shifts and job satisfaction among nurses of Ain Shams university hospitals. The Egyptian Journal of Community Medicine, 34(2), 75-86. https://doi.org/10.21608/ejcm.2016.655

Horton Dias, C., \& Dawson, R. M. (2020). Hospital and Shift Work Influences on Nurses' Dietary Behaviours: A Qualitative Study. Workplace Health and Safety, 68(8), 374383. https://doi.org/10.1177/2165079919890351

Min Ju, K., Kuk Hui, S., Hyun Young, P., Dong Ju, C., Chang Hwan, Y., Hea Young, L., Eun Young, C., \& Myeong Chan, C. (2013). Association Between Shift Work and Obesity Among FemaleNnurses: Korean Nurses' Survey. BMC Public Health, 13(1), 115.http://www.redibw.de/db/ebsco.php/search.ebscohost.com/login.aspx?direct=true\&db=a2h\&AN=93622557\&site=ehost-live

Monaghan, T., Dinour, L., Liou, D., \& Shefchik, M. (2018). Factors Influencing the Eating Practices of Hospital Nurses During Their Shifts. Workplace Health and Safety, 66(7), 331-342. https://doi.org/10.1177/2165079917737557

Samhat, Z., Attieh, R., \& Sacre, Y. (2020). Relationship between night shift work, eating habits and BMI among nurses in Lebanon. BMC Nursing, 19(1), 4-9. https://doi.org/10.1186/s12912-020-00412-2

Shafi, Z., Arif, S., \& Nasir, A. (2020). Association of long duty hours and unhealthy dietary habits among nurses at private and public sector in Karachi, Pakistan. Journal of the Liaquat University of Medical and Health Sciences, 19(1), 55-61. https://doi.org/10.22442/jlumhs.201910662

Siew Hong, H. (2019). Eating Behaviour and Its Associations with Overweight among Nurses on Shift Duty in Teaching Hospital. Medicine \& Health, 14(1), 68-77. https://doi.org/10.17576/mh.2019.1401.06

Tai, S. Y., Lin, P. C., Chen, Y. M., Hung, H. C., Pan, C. H., Pan, S. M., Lee, C. Y., Huang, C. T., \& Wu, M. T. (2014). Effects of marital status and shift work on family function among registered nurses. Industrial Health, 52(4), 296-303. https://doi.org/10.2486/indhealth.2014-0009

Witkoski, A., \& Dickson, V. V. (2010). Hospital Staff Nurses' Work Hours, Meal Periods, and Rest Breaks. AAOHN Journal, 58(11), 489-497. https://doi.org/10.3928/08910162-20101027-02

Wong, H., Wong, M. C. S., Wong, S. Y. S., \& Lee, A. (2010). The association between shift duty and abnormal eating behaviour among nurses working in a major hospital: A cross-sectional study. International Journal of Nursing Studies, 47(8), 1021-1027. https://doi.org/10.1016/j.ijnurstu.2010.01.001 